\title{
Toward Modelling of Transformational Change Processes in Farm Decision-Making
}

\author{
S. Huet ${ }^{1 *}$, C. Rigolot ${ }^{2 *}$, Q. Xu², Y. De Cacqueray-Valmenier ${ }^{1}$, I. Boisdon ${ }^{2}$ \\ ${ }^{1}$ Lisc, Irstea, Aubière, France \\ ${ }^{2}$ Université Clermont Auvergne, Agro ParisTech, Inra, Irstea, VetAgro Sup, UMR Territoires, \\ Clermont-Ferrand, France \\ Email: *sylvie.huet@irstea.fr, ${ }^{\star}$ cyrile.rigolot@inra.fr
}

How to cite this paper: Huet, S., Rigolot, C., Xu, Q., De Cacqueray-Valmenier, Y. and Boisdon, I. (2018) Toward Modelling of Transformational Change Processes in Farm Decision-Making. Agricultural Sciences, 9, 340-350.

https://doi.org/10.4236/as.2018.93024

Received: January 31, 2018

Accepted: March 23, 2018

Published: March 26, 2018

Copyright (C) 2018 by authors and Scientific Research Publishing Inc. This work is licensed under the Creative Commons Attribution International License (CC BY 4.0).

http://creativecommons.org/licenses/by/4.0/

\begin{abstract}
In the coming decades, agricultural systems will have to adapt to tremendous challenges. Behavioral models have important potential to better understand and steer changes toward sustainability brought about by this context. Relying on a literature review, we distinguish incremental changes (extensions of what is already done) and transformational changes, which involve the reorientation of a considerable amount of farming activities. Transformational changes are particularly important in the context of global change. Existing integrated modelling frameworks based on behavioral theories are suited for incremental changes, but remain limited for transformational changes. Qualitative studies provide important insights on two key aspects of transformational changes, learning and social relations, but they have not been explicitly oriented toward computer modelling yet. Based on this literature and three seminal decision-making approaches, we propose a description of transformational change processes in farm decision-making, as a first step toward an implementation in agent-based models.
\end{abstract}

\section{Keywords}

Transformation, Adaptation, Modelling, Decision-Making, Farmer

\section{Introduction}

In the coming decades, agriculture will be faced with huge challenges: agricultural systems will have to decrease their environmental impact while producing enough food for a growing population. Meanwhile, they will have to cope with important uncertainties: climatic, economic, politic... [1] [2] [3]. In this context, agricultural systems will have to adapt to remain sustainable.

*These two authors contributed equally to the paper. 
To understand agricultural adaptations and transitions, modelling has become an essential methodology [4] [5] [6]. Until recently, most agronomic models remained mainly driven by an economic optimization approach, focusing on the farm and its technical and economic characteristics [7] [8]. They generally present the farm decision-making in terms of factors, barriers and motivations [9]. To better understand changing dynamics, [10] identify a need for integrated and dynamic modelling frameworks, based on explicit and well-motivated cognitive and social behavioral theories. Complementarily, [8] shows that adaptation is better understood by focusing on the "how" instead of "why", and by considering the time dynamics of the farmer's relationships to others. The modelling of decision-making has grown from the review of [7] more than 10 years ago to the recent one of [6]. Insights from psychology have been more and more integrated in the models in order to understand how farmers decide, innovate and change. Among the various models of farmer decision-making, the agent-based models have particularly developed in the last few years. Agent-based models integrate cognitive and social behavioral theories, as well as farmers' relation with other people and the environment [4] [11] [12]. Moreover, studying the evolution of a population of interdependent farmers is particularly appropriate to design and test different policy options favoring innovation or adaptation.

In this paper, we first introduce the notions of incremental and transformational changes in agriculture, relying on a literature review on adaptations. Transformational changes are particularly important in the context of global change, to cope with the tremendous challenges ahead. Then, we show that existing modelling frameworks based on behavioral theories are well suited for the description of incremental changes, but remain limited for understanding transformational changes. We also point out that key qualitative studies have described transformational changes, but a conceptualization clearly oriented toward modelling is missing. Finally, we propose a description of transformational change processes in farm decision-making, with the perspective of implementation in agent-based models.

\section{Incremental and Transformational Changes}

Recently, the focus has progressively shifted towards transformational change in agriculture as a response to global change [13] [14]. Transformational change can be distinguished from "incremental adaptations", which have been described as extensions of "what is already being done" [15]. By contrast, [15] identify at least three classes of adaptations as transformational: "1) those that are adopted at a much larger scale or intensity; 2) those that are truly new to a particular region or resource system; and 3) those that transform places and shift locations". As incremental adaptations, transformational changes can be autonomous or planned, responsive or proactive [13]. Following another definition, transformational adaptation involves not only radical technical change but also changes in 
"meaning making" (i.e. changes in intentions and attitude behind behavior) [16]. This last definition is close to the concept of "major change" proposed by [17], with the example of conversion to organic farming, which is also considered by [13] as a transformational adaptation. Indeed, a major change involves "the reorientation of a considerable amount of farming activities or resources, for example through transition from commercial farming to care farming or other diversification activity" by contrast with a minor change, which is just "an alteration to farming activities which does not change the direction or focus to the farm system" [17].

To cope with challenges ahead, incremental adaptation will not be enough: transformational changes are required [13] [15]. For example, incremental adaptation will only provide resilience to modest climate change and some larger scale adaptation options will be required in order to ensure long-term viability [18]. Reducing greenhouse gas emissions to sustainability targets also implies transformational changes [16] [18]. Transformational changes are required, but their implementation remains a tremendous challenge. For example, in the European context, organic agriculture is far from having grown as much as the demand for organic products, even in places where conversion would be obviously profitable for farmers [19]. To foster transformational changes of agricultural systems, modelling can play an important role [4]. In the next section, however, we show that the current state of the art is limited when it comes to understanding and modelling transformational change processes on farms.

\section{The Modelling of Decision-Making in Agriculture Is Focused on Incremental Changes}

Many researchers and policy makers still tend to view the farm throughout a simplistic lens [4] [5] [6] [20]. Yet, some conceptualizations have been proposed to show how various factors influence farmer's decision, including education, professional experience, information network and farm characteristics [7] [10] [21]. However, according to [20], most of these studies do not consider the dynamic process by which actions are decided in specific situations. To overcome this limit, Martin-Clouaire [20] proposes a framework for modelling a flexible operational decision-making in agriculture. This framework reconciles three seminal cognitive decision-making approaches by proposing a revised Belief, Desire, Intention rational agency architecture [22]. The key role of heuristics is incorporated by giving the possibility to implement the "Decision Ladder" process control proposed by [23], or the recognition-primed decision protocols [24] to represent the various ways people decide (i.e. relying on more or less reasoning in the process and/or their experience as tacit standard for expectations to find out quickly a satisfying solution). Overall, this framework structures the decision-making behavior along a set of cognitive processes such as perception, interpretation, goal reasoning, planning and judgement to model a dynamic adaptation of the farmer to the situation [20]. 
Although Martin-Clouaire's flexible view of decision-making is particularly relevant for adaptation issues, it remains primarily focused on incremental changes, as most of models of farmers' decision-making. Indeed, [20] identifies two main limits to his framework: 1) a poor representation of learning; and 2) "a restrictive view of farmer as single agent, paying little attention to social relations". As we develop in the next section, these two weak elements (learning and social relations) are precisely crucial elements to deal with transformational adaptation.

\section{Key Factors of Transformational Changes and First Steps toward a Conceptualization}

To study transformational change such as conversion to organic farming, [25] argue for the study of trajectories. This consists in studying the family-farming system in the medium and long runs [26]. Such trajectory analyses are typically based on comprehensive interviews with farmers. They reveal the importance of key factors, such as farmers trying new methods on the farm, peer group exchanges and collective co-construction of changes [27]. Then, following this principle, many studies have drawn typical trajectories of adaptation [28] [29] [30] [31]. These studies appear as an appropriated source of information to conceive and evaluate agent-based models. Particularly, [32] have shown how farmers learn a new practice through experimentation (on their farm or another farm), possibly discussing them with farmers or advisors. For this author, learning continues until what farmers have tested or seen can be assessed, based on references associated to their usual practice. All these studies show how farmers change not only their practices, but also possibly the entire view they have of their profession and their way of life [33].

These agent-level elements are typically not included in most existing modelling frameworks, such as proposed by [20]. This is also true for the collective construction observable at the population level. Indeed, according to the review of [34] current "representations [of farm evolution] are built according to a stable professional norm of the evolving farming system that doesn't allow important shift in the farming system over the long run". A growing literature is currently challenging these representations, arguing norms evolve during the adaptation of farmers and from interactions between farmers [35]. In a key contribution toward a comprehensive conceptualization of transformational changes, Sutherland et al. [17] introduce the idea of a "triggering change cycle". For these authors, "as a result of path dependency, major [transformational] changes in farming practices primarily occur in response to "trigger events", after which farm managers intensify their considerations for the options open to them, and may set a new course of action". Additionally, [36] develop the concept of "good farmer" to highlight farmers' value changes in the transformational process. [37] [17] conceptualization of farmer engagement in the transformational change and the associated cognitive effort is consistent with socio-psychological theories 
such as the "elaboration likelihood model" [38], as well as the transition management theory [39]. Although highly relevant, this conceptualization remains limited in the way the interactions between the farmer and other actors, especially peers, are dynamically represented. Complementarily, other studies focus on the role of networks rather than on the sole farm level. Particularly, [40] have begun to identify key characteristics of social and informational networks for transformational changes (strong access to knowledge and weak ties). The next section is intended to go further toward an implementation of transformational change in agent-based models, with a focus on learning and social relations specific dimensions of transformational change.

\section{Modelling Transformational Change Processes: A Proposal}

Similarly to Martin-Clouaire's framework [20], our proposal is based on a critical analysis of three seminal decision-making approaches. They have been grounded from a social or anthropological perspective instead a cognitive one: 1) The management study of [41] deals with the decision process of an organization facing a totally new situation diagnosed as a problem; 2) The diffusion of innovation theory [42], initially focused on farmers, particularly stresses out the role of network of peers who inform and reinsure farmers. These roles has been modeled by [43] [44]; 3). In social psychology, the Theory of Planned Behavior (TPB), extended from the theory of reasoned action [45] [46] stresses out the role of the intention to act in the decision-making process. This intention is not only based on self-assessment of the action, but also on its perceived value from farmer's relevant relations (i.e. subjective norm), as well as the farmer's feeling of control over the performance of the action.

Consistently with Sutherland et al. [17], a proper model of a transformational change process can be based on two different phases for farmers and two different related regimes: 1) the path-dependency regime during which only incremental changes occur and 2) the transitory regime which is specific to a transformational change, allowing to transit from a stable path-dependency phase to another one. The dynamics associated to these regimes are different.

The first regime is the one for "incremental" adaptations in a stable context, or perceived as such due to various socio-cognitive barriers [47]. Farmers' references, values or norms do not change; some strategic change can occur but remain "under control" from the farmers' point of view, allowing them to make a living from their practice and keeping their "good farmer" identity [36]. Farmers evaluate possible changes in terms of similarity to previous changes [24]. The more experiences they have, the less they rely on peers or external sources to assess and decide. The conceptual framework of [20] appears totally relevant for modelling this phase.

Entering in the second regime begins with a realization. This can be due to one or several "trigger events" [17] [27] [31]. Trigger events can be related to 
economic difficulties, climatic or health issues amplified by the instability of the context (external or internal to the farming household). The farmer may also come to realize that his system has become untenable [48]. This phase is a particularly uncomfortable state in which farmers doubt the relevance of their definition of "good farming". Then, this state makes them open up to different opportunities, options and different ways of farming.

Farmers actively look [40] [41] for more convenient practices and associated "good farming" definitions, remaining open to opportunities which can help them evolve. Farmers are highly sensitive to new information, especially when their uncertainty is strong [49]. They favor the more consistent one with their moral values and current unsatisfied goals. Developing a new complex option for adaptation is often very costly in terms of time, cognition and affect, as shown by [41] and consistently with [38]. Therefore, farmers focus quickly on learning and assessment of one possible transformational strategy at once. They can also return to the previous regime [49] if new information comforts their current set of practices.

Change is closely related to the feeling of control over the considered practice [45], and more generally to the uncertainty in the process. During the whole transitory phase, the farmer acts to reduce uncertainty (by choosing more confident source of information, preferring simpler options, trying new things on his farm, looking for relationships and knowledge reinforcing already made choices [10] [41] [49] [50] [51] [52]. Farmers are susceptible to changing their sources of information, the peers to whom they talk, and their advisers [41] [42] in order to find information and knowledge about a new practice, as well as to be reassured after they have chosen to adopt it. Their social network is dynamic: during the process, farmers adopt a more effective social environment in which to perform the new practice for achieving a desired outcome. They can also change their idea of what is a "good farmer" [31] [36], as well as the criteria used to evaluate their practice (for example, by giving more weight to the environmental impacts). To implement the process in agent-based models, the intent to adopt a new practice (as defined by the TPB) can be used as a proxy. The intent becomes high when: 1) the searching farmer has observed and memorized enough successful experiences of other farmers; 2) his social environment is perceived as sufficiently in favor of this new practice; 3) he feels confident enough in his ability to perform the practice. The proxy can be compared to a personal threshold beyond which change is considered. This threshold varies from one farmer to another, depending on how risk-averse or risk-taking he is [53].

After transformational change is engaged, the next issue is to understand how farmers re-enter a path-dependency period. According to the diffusion of innovation theory [42], the decision-making process is finished since the "new idea" is not "new" anymore for the decider and totally integrated as his own practice. During all the process, the farmer has made operational decisions driven both by 
the previous practice and the new practice, with the aim to acquire knowledge and reduce uncertainty. When the intention to remain in the transformed system is high enough, the farmer enters again a stable period dominated by incremental adaptations.

\section{Discussion and Perspectives}

From the literature, we have pointed out the current need for transformational changes in agriculture. Modelling decision-making is promising, but it remains focused on incremental changes despite important qualitative studies on transformational changes [17]. Our proposal for a description of transformational change processes is an important step further toward the implementation of transformational change in computer models. As a perspective, we believe that agent-based models are particularly interesting to tackle transformational changes, rather than sole farm models, due to the crucial importance of collective aspects in decision-making processes. Moreover, existing agent-based models provide a relevant basis and can be improved in the light of our proposals. For example, the agent-based model of [54] considers the social influence as the key to enter into a decision process. In this model, if the initial opinion about the change is negative or low, the agents do not consider the decision. They are not really considering the innovation until their social opinion is high enough. Our description of transformational change provides new insights on key parameters, processes and threshold effects to be implemented in such models to tackle transformational changes.

It is important to point out that transformational change is neither opposed to nor independent from incremental changes: as [48], we have an integrated view of incremental and transformative adaptations in a unique cycle to adapt to global change. Finally, while some behavioral processes may remain fundamentally impossible to model [4], we believe behavioral models of transformational change could provide important insights to foster the required rapid sustainability transformations.

\section{Acknowledgements}

We acknowledge funding from the Auvergne-Rhône-Alpes region (France).

\section{References}

[1] Darnhofer, I., et al. (2010) Adaptiveness to Enhance the Sustainability of Farming Systems. A Review. Agronomy for Sustainable Development, 30, 545-555. https://doi.org/10.1051/agro/2009053

[2] Tscharntke, T., et al. (2012) Global Food Security, Biodiversity Conservation and the Future of Agricultural Intensification. Biological Conservation, 151, 53-59. https://doi.org/10.1016/j.biocon.2012.01.068

[3] Tilman, D., et al. (2002) Agricultural Sustainability and Intensive Production Practices. Nature, 418, 671. https://doi.org/10.1038/nature01014 
[4] Brown, C., et al. (2017) Behavioral Models of Climate Change Adaptation and Mitigation in Land-Based Sectors. Wiley Interdisciplinary Reviews. Climate Change, 8 , e448. https://doi.org/10.1002/wcc.448

[5] Janssen, S. and van Ittersum, M.K. (2007) Assessing Farm Innovations and Responses to Policies: A Review of Bio-Economic farm Models. Agricultural Systems, 94, 622-636. https://doi.org/10.1016/j.agsy.2007.03.001

[6] Robert, M., Thomas, A. and Bergez, J.-E. (2016) Processes of Adaptation in Farm Decision-Making Models. A Review. Agronomy for Sustainable Development, 36, 64. https://doi.org/10.1007/s13593-016-0402-x

[7] Edwards-Jones, G. (2006) Modelling Farmer Decision-Making: Concepts Progress and Challenges. Animal Science, 82, 783-790. https://doi.org/10.1017/ASC2006112

[8] McGregor, M.J., Rola-Rubzen, M.F. and Murray-Prior, R. (2001) Micro and Macro-Level Approaches to Modelling Decision-Making. Agricultural Systems, 69, 63-83. https://doi.org/10.1016/S0308-521X(01)00018-X

[9] Latruffe, L., Nauges, C. and Desjeux, Y. (2013) The Role of Economic Factors in Driving Conversion to Organic Farming. Innovations Agronomiques, 32, 259-269.

[10] Feola, G. and Binder, C.R. (2010) Toward an Improved Understanding of Farmers' Behaviour: The Integrative Agent-Centred (IAC) Framework. Ecological Economics, 69, 2323-2333. https://doi.org/10.1016/j.ecolecon.2010.07.023

[11] Goldstone, R.L. and Janssen, M.A. (2005) Computational Models of Collective Behavior. Trends in Cognitive Sciences, 9, 424-430.

https://doi.org/10.1016/j.tics.2005.07.009

[12] Heckbert, S., Baynes, T. and Reeson, A. (2010) Agent-Based Modeling in Ecological Economics. Annals of the New York Academy of Sciences, 1185, 39-53. https://doi.org/10.1111/j.1749-6632.2009.05286.x

[13] Rickards, L. and Howden, S.M. (2012) Transformational Adaptation: Agriculture and Climate Change. Crop and Pasture Science, 63, 240-250.

https://doi.org/10.1071/CP11172

[14] Pelling, M., O’Brien, K. and Matyas, D. (2015) Adaptation and Transformation. Climatic Change, 133, 113-127. https://doi.org/10.1007/s10584-014-1303-0

[15] Kates, R.W., Travis, W.R. and Wilbanks, T.J. (2012) Transformational Adaptation When Incremental Adaptations to Climate Change Are Insufficient. Proceedings of the National Academy of Sciences of the United States of America, 109, 7156-7161. https://doi.org/10.1073/pnas.1115521109

[16] O’Brien, K. and Hochachka, G. (2010) Integral Adaptation to Climate Change. Journal of Integral Theory \& Practice, 5, 89-102.

[17] Sutherland, L.-A., Gottsa, N., Slee, B., Blackstock, K., et al. (2012) Triggering Change: Towards a Conceptualisation of Major Change Processes in Farm Decision-Making. Journal of Environmental Management, 104, 142-151. https://doi.org/10.1016/j.jenvman.2012.03.013

[18] Herrero, M., Wirsenius, S., Henderson, B., Rigolot, C., et al. (2015) Livestock and the Environment: What Have We Learned in the Past Decade? Annual Review of Environment and Resources, 40, 177-202. https://doi.org/10.1146/annurev-environ-031113-093503

[19] Dedieu, M.S., et al. (2017) The Organic Farms: Which Economic Performances? Les acteurs économiques et l'environnement, I. References, Editor 2017. 44. https://www.insee.fr/fr/statistiques/3280932?sommaire $=3280952$ 
[20] Martin-Clouaire, R. (2017) Modelling Operational Decision-Making in Agriculture. Agricultural Sciences, 8, 527-544. https://doi.org/10.4236/as.2017.87040

[21] McCown, R.L. (2005) New Thinking about Farmer Decision Makers. In: Hatfield, J.L., Ed., The Farmer's Decision: Balancing Economic Agriculture Production with Environmental Quality, Soil and Water Conservation Society, Ankeny, 11-44.

[22] Bratman, M.E., Israel, D.J. and Pollack, M.E. (1988) Plans and Resource-Bounded Practical Reasoning. Computational Intelligence, 4, 349-355. https://doi.org/10.1111/j.1467-8640.1988.tb00284.x

[23] Rasmussen, J. (1976) Outlines of a Hybrid Model of the Process Plant Operator. In: Sheridan, T.B. and Johannsen, G., Eds., Monitoring Behavior and Supervisory Control, Springer, Boston, MA, 371-383.

[24] Klein, G. (1997) The Recognition-Primed Decision (RPD) Model: Looking Back, Looking Forward. In: Zsambok, C.E. and Klein, G., Eds., Expertise: Research and Applications. Naturalistic Decision Making, Lawrence Erlbaum Associates, Inc., Hillsdale, NJ, 285-292.

[25] Lamine, C. and Bellon, S. (2009) Conversion to Organic Farming: A Multidimensional Research Object at the Crossroads of Agricultural and Social Sciences. A Review. Agronomy for Sustainable Development, 29, 97-112. https://doi.org/10.1051/agro:2008007

[26] Moulin, C.H., Ingrand, S., Lasseur, J., Madelrieux, S., Napoléone, M., Pluvinage, J. and Thénard, V. (2008) Understanding and Analyzing Organisational and Livestock Management Practices Changesin Farms: Methodological Proposal. In: Dedieu, B., Leclerc, B., Moulin, C.H., Tichit, M., Eds., L'Élevage en mouvement. Flexibilité et adaptation des exploitations d' herbivores, Éditions Quae, Versailles, 23-36.

[27] Barbier, C., Cerf, M. and Lusson, J.-M. (2015) Life Stories of Farmers to Low Input Practices: The Pleasures Associated to the Change of Practices. Activités, 12, 27.

[28] Boisdon, I., et al. (2013) Typology of Trajectories of Conversion to Organic Farming of Mountainous Dairy Farms. Rencontres autour des recherches sur les ruminants.

[29] Chantre, E., Cerf, M. and Bail, M.L. (2015) Transitional Pathways towards Input Reduction on French Field Crop Farms. International Journal of Agricultural Sustainability, 13, 69-86. https://doi.org/10.1080/14735903.2014.945316

[30] Lamine, C., Meynard, J.M., Perrot, N. and Bellon, S. (2009) Analysis of Forms of Transition toward More Ecological Farming: The Organic Farming and the Integrated Protection. Innovations Agronomiques, 4, 483-493.

[31] Alavoine-Mornas, F. and Madelrieux, S. (2014) Paths to Organic Farming. A Variety of Process. Économie Rurale, 339-340, 65-79.

[32] Chantre, E. and Cardona, A. (2014) Trajectories of French Field Crop Farmers Moving toward Sustainable Farming Practices: Change, Learning, and Links with the Advisory Services. Agroecology and Sustainable Food Systems, 38, 573-602. https://doi.org/10.1080/21683565.2013.876483

[33] Coquil, X., Dedieu, B. and Béguin, P. (2017) Professional Transitions towards Sustainable Farming Systems: The Development of Farmers' Professional Worlds. Work, 57, 325-337. https://doi.org/10.3233/WOR-172565

[34] Coquil, X., Dedieu, B. and Beguin, P. (2010) How Do Livestock and Crop Sciences Represent Evolutions of Farming Systems? A Review. In: Binder, C.R. and Feola, G., Eds., 9th European IFSA Symposium, University of Natural Resources and Applied Life Sciences, Vienne, Austria, 1255-1266. 
[35] Farrow, K., Grolleau, G. and Ibanez, L. (2017) Social Norms and Pro-Environmental Behavior: A Review of the Evidence. Ecological Economics, 140, 1-13. https://doi.org/10.1016/j.ecolecon.2017.04.017

[36] Sutherland, L.-A. (2013) Can Organic Farmers Be "Good Farmers"? Adding the "Taste of Necessity" to the Conventionalization Debate. Agriculture and Human Values, 30, 429-441. https://doi.org/10.1007/s10460-013-9424-Z

[37] Sutherland, L.-A. (2011) "Effectively Organic": Environmental Gains on Conventional Farms through the Market? Land Use Policy, 28, 815-824. https://doi.org/10.1016/j.landusepol.2011.01.009

[38] Petty, R.E. and Cacioppo, J.T. (1986) The Elaboration Likelihood Model of Persuasion. In: Berkowitz, L., Ed., Advances in Experimental Social Psychology, Academic Press, Cambridge, MA, 123-205.

[39] Geels, F.W. (2004) From Sectoral Systems of Innovation to Socio-Technical Systems: Insights about Dynamics and Change from Sociology and Institutional Theory. Research Policy, 33, 897-920. https://doi.org/10.1016/j.respol.2004.01.015

[40] Dowd, A.-M., Marshall, N., Fleming, A., et al. (2014) The Role of Networks in Transforming Australian Agriculture. Nature Climate Change, 4, 558-563. https://doi.org/10.1038/nclimate2275

[41] Mintzberg, H., Raisinghani, D. and Theoret, A. (1976) The Structure of "Unstructured” Decision Processes. Administrative Science Quarterly, 21, 246-275. https://doi.org/10.2307/2392045

[42] Rogers, E.M. (1995) Diffusion of Innovations. 4th Edition, The Free Press, a Division of Simon \& Schuster Inc., New York.

[43] Valente, T.W. (1995) Networks Models of the Diffusion of Innovations. Hampton Press, Inc., Cresskill, NJ, 171.

[44] Valente, T.W. (1996) Social Network Thresholds in the Diffusion of Innovations. Social Networks, 18, 69-89. https://doi.org/10.1016/0378-8733(95)00256-1

[45] Ajzen, I. (1985) From Intentions to Actions: A Theory of Planned Behavior. In: Kuhl, J. and Beckmann, J., Eds., Action Control: From Cognition to Behavior, Springer, Berlin, Heidelberg, 11-39. https://doi.org/10.1007/978-3-642-69746-3_2

[46] Fishbein, M. (1979) A Theory of Reasoned Action: Some Applications and Implications. Nebraska Symposium on Motivation, 27, 65-116.

[47] Moser, S.C. and Ekstrom, J.A. (2010) A Framework to Diagnose Barriers to Climate Change Adaptation. Proceedings of the National Academy of Sciences of the United States of America, 107, 22026-22031. https://doi.org/10.1073/pnas.1007887107

[48] Park, S.E., et al. (2012) Informing Adaptation Responses to Climate Change through Theories of Transformation. Global Environmental Change, 22, 115-126. https://doi.org/10.1016/j.gloenvcha.2011.10.003

[49] Öhlmér, B., Olson, K. and Brehmer, B. (1998) Understanding Farmers' Decision-Making Processes and Improving Managerial Assistance. Agricultural Economics, 18, 273-290.

[50] Ajzen, I. (1991) The Theory of Planned Behavior. Organizational Behavior and Human Decision Processes, 50, 179-211. https://doi.org/10.1016/0749-5978(91)90020-T

[51] Deffuant, G., Amblard, F., et al. (2002) Agent-Based Simulation of Organic Farming Conversion in Allier Département. In: Janssen, M.A., Ed., Agent-Based Simulation 
of Organic Farming Conversion in Allier Département, Edward Elgar Publishing Limited, Cheltenham, UK; Northampton, USA, 158-187.

[52] Sutherland, L.-A., Gabriel, D., Pascual, U., et al. (2012) The "Neighbourhood Effect": A Multidisciplinary Assessment of the Case for Farmer Co-Ordination in Agri-Environmental Programmes. Land Use Policy, 29, 502-512. https://doi.org/10.1016/j.landusepol.2011.09.003

[53] Willock, J., .Deary, I.J., et al. (1999) Farmers' Attitudes, Objectives, Behaviors, and Personality Traits: The Edinburgh Study of Decision-Making on Farms. Journal of Vocational Behavior, 54, 5-36. https://doi.org/10.1006/jvbe.1998.1642

[54] Deffuant, G., Huet, S. and Amblard, F. (2005) An Individual-Based Model of Innovation Diffusion Mixing Social Value and Individual Payoff Dynamics. American Journal of Sociology, 110, 1041-1069. 